\title{
POSS-Containing Polymethacrylates on Cellulose-Based Substrates: Immobilization and Ceramic Formation
}

\author{
Christian Rüttiger ${ }^{1}{ }^{\mathbb{D}}$, Steffen Vowinkel ${ }^{1}$, Nicole Herzog ${ }^{1}$, Kathrin Hofmann ${ }^{2}$, \\ Emanuel Ionescu ${ }^{3}$ (D) and Markus Gallei ${ }^{1, *(D)}$ \\ 1 Ernst-Berl Institute of Technical and Macromolecular Chemistry, Technische Universität Darmstadt, \\ Alarich-Weiss-Straße 4, 64287 Darmstadt, Germany; c.ruettiger@mc.tu-darmstadt.de (C.R.); \\ s.vowinkel@mc.tu-darmstadt.de (S.V.); herzog@smartmem.tu-darmstadt.de (N.H.) \\ 2 Eduard-Zintl Institute of Inorganic and Physical Chemistry, Technische Universität Darmstadt, \\ Alarich-Weiss-Str. 12, 64287 Darmstadt, Germany; hofmann@ac.chemie.tu-darmstadt.de \\ 3 Materials Science Department, Technische Universität Darmstadt, Alarich-Weiss-Straße 2, \\ 64287 Darmstadt, Germany; ionescu@materials.tu-darmstadt.de \\ * Correspondence: m.gallei@mc.tu-darmstadt.de
}

Received: 31 October 2018; Accepted: 4 December 2018; Published: 6 December 2018

\begin{abstract}
The combination of cellulose-based materials and functional polymers is a promising approach for the preparation of porous, biotemplated ceramic materials. Within this study, cellulose substrates were functionalized with a surface-attached initiator followed by polymerization of (3-methacryloxypropyl)heptaisobutyl-T8-silsesquioxane (MAPOSS) by means of surface-initiated atom transfer radical polymerization (ATRP). Successful functionalization was proven by infrared (IR) spectroscopy as well as by contact angle (CA) measurements. Thermal analysis of the polymer-modified cellulose substrates in different atmospheres (nitrogen and air) up to $600{ }^{\circ} \mathrm{C}$ led to porous carbon materials featuring the pristine fibre-like structure of the cellulose material as shown by scanning electron microscopy (SEM). Interestingly, spherical, silicon-containing domains were present at the surface of the cellulose-templated carbon fibres after further ceramisation at $1600{ }^{\circ} \mathrm{C}$, as investigated by energy dispersive X-ray spectroscopy (EDS) and X-ray diffraction (XRD) measurements.
\end{abstract}

Keywords: immobilized polymers; controlled polymerizations; ceramic precursors; cellulose; ATRP

\section{Introduction}

The preparation of hierarchically ordered and multifunctional materials is an important concept in nature, which has attracted enormous attention of scientists over the last decades [1,2]. Especially current efforts in the fields of nanotechnology for mimicking and developing nanoscaled structured materials in artificial manners are of growing interest. The fabrication of hierarchically structured porous materials by synthesis and assembly of e.g., spheres, nanowires, nanorods, nanotubes, fibres for the preparation of smart membranes, or inverse opals with adjustable 3-dimensional structures has gained considerable attention due to the tremendous potential for various applications. Such porous materials and combinations thereof are highly promising candidates in fields of catalysis, separation, sensors, optics, and biomedicine [3-9]. As a feasible preparation route, different templating strategies have been applied for controlling shape and size of the final materials after removal of the template structure [10-18]. Current approaches are moving forward to establishing novel preparative strategies to produce for instance tailor-made silicon-based polymers [19] as suitable precursors for advanced ceramics [20]. Within this context, studies comprising the molecular 
polymer architecture and interaction with filler or template materials are of crucial importance [21,22]. Consequently, there is a strong demand for developing designed preceramic polymers featuring tailored polymer architectures. Within this field, polysiloxanes and polysilsesquioxanes have been proven to have excellent chemical and physical properties and therefore have been extensively used as ceramic precursors for the synthesis of silicon oxycarbide (SiOC) ceramic materials via pyrolysis in inert or reactive atmosphere $[16,23,24]$. On the other hand, organic cellulose-based substrates feature an adjustable morphology for tailoring the porosity. Therefore, the use of functional papers in the advanced technological fields of printed electronics, capacitors, and sensors are steadily growing [25-29]. Thus, functional papers that provide a direct and technologically straight-forward control over the wettability and functionality through polymer modification are desirable as platforms for microfluidics or sensing applications [30,31]. Paper-derived ceramics were used for the preparation of biotemplated functional and hierarchically ordered materials, which are technologically relevant as micro filters or catalyst platforms [32]. Typically, cellulose-based templates were chemically infiltrated with gases or fluids followed by thermal treatment at temperatures of approximately 850 to $900{ }^{\circ} \mathrm{C}$. For instance, ceramic materials based on $\mathrm{SiC}$ [33], $\mathrm{SiC} / \mathrm{Si}_{3} \mathrm{~N}_{4}$ [34], $\mathrm{TiC}$ [35], $\mathrm{Al}_{2} \mathrm{O}_{3}$ [36], or $\mathrm{TiO}_{2}$ have been prepared. Especially the Greil group reported many interesting examples for the preparation of paper-derived ceramic materials in the last two decades and the authors pointed out that the morphology and porosity of the final hybrid materials can be tailored by the organic precursor architectures [37-43]. The presented technologies rely on the infiltration of the porous cellulose-based substrates, however, some recent advances show that functionalization by means of controlled radical polymerizations and the use of well-defined polymers can be advantageous with respect to the efficiency of polymer grafting and for maintaining the organic-templated morphology [29,44-48].

Various substrates have been functionalized by using the so-called "grafting-from" methodology leading to considerably higher polymer grafting densities at the substrate compared to the "grafting-onto" process due to sterical hindrance in the latter case $[49,50]$. Controlled polymerization routes lead to precisely defined polymers in regard to their constitution, chain length, and molar masses. Common strategies include atom transfer radical polymerization (ATRP), nitroxidemediated polymerization (NMP), and reversible addition-fragmentation chain transfer (RAFT) polymerization [51-53]. To the best of our knowledge, the preparation of well-defined preceramic polysilsesquioxanes [54] grafted from the surface of biotemplate cellulose-substrates by means of controlled polymerization has not been investigated yet.

In the present study, the ATRP of (3-methacryloxypropyl)heptaisobutyl-T8-silsesquioxane (MAPOSS) for the immobilization of the corresponding poly(MAPOSS) on cellulose-based substrates is reported. The functionalization with ATRP-initiator and PMAPOSS has been studied by contact angle measurements, while polymer chains obtained by the addition of free ATRP-initiator were characterized with respect to molar masses and constitution by size-exclusion chromatography. The conversion of the hybrid functional cellulose materials into a C/SiC-based ceramic material is investigated by thermogravimetric analysis (TGA). The final carbon/ceramic hybrids are investigated by scanning electron microscopy (SEM) in combination with energy dispersive X-ray spectroscopy (EDX), X-ray diffraction (XRD), and Raman spectroscopy revealing preservation of the pristine cellulose fibres in form of carbon fibres featuring spherical particles of $\mathrm{SiC}$ at the fibre surface.

\section{Experimental Section}

\subsection{Materials}

All solvents and reagents were purchased from Alfa Aesar (Haverhill, MA, USA), Sigma-Aldrich (St. Louis, MA, USA), Fisher Scientific (Hampton, NH, USA), and ABCR (Karlsruhe, Germany), and used as received unless otherwise stated. Deuterated solvents were purchased from Sigma-Aldrich. (3-Methacryloxypropyl) heptaisobutyl-T8-silsesquioxane (iBuPOSSMA) (99\%) was purchased from Hybrid Plastics (Hattiesburg, MS, USA) and used after recrystallization from methanol. $\mathrm{Cu}(\mathrm{I}) \mathrm{Cl}$ was 
washed five times with glacial acetic acid and ethanol. $N-, N_{-}, N^{\prime}-, N^{\prime}-, N^{\prime \prime}$-Pentamethyl-diethylenetriamine (PMDETA), anisole, 2-bromo-iso-butyric tert-butylester ( $t$ Bbib) were degassed and stored under argon atmosphere or in a glovebox. Toluene was distilled from sodium/benzophenone. The copper complexes were freshly prepared in anisole and treated in the glovebox. The ATRP initiator 3-(2-bromoisobutyrate) propyl trichlorosilane was synthesized in modification as described elsewhere [55]. Commercially available filter discs (grade $3 \mathrm{hw}$, Munktell, Ahlstrom, Stockholm, Sweden) were used as paper substrates featuring diameters of $90 \mathrm{~mm}$ and a density of $65 \mathrm{~g} \cdot \mathrm{m}^{-2}$. The paper discs are composed of bleached alpha cellulose consisting of pine and spruce fibres featuring a porosity of 8 to $12 \mu \mathrm{m}$. All syntheses steps were conducted in nitrogen or argon atmosphere using Schlenk techniques or a glovebox.

\subsection{Methods}

Standard size-exclusion chromatography (SEC) was performed with a system composed of a 1260 IsoPump-G1310B-(Agilent Technologies, Santa Clara, CA, USA), a 1260 VW detector-G1314F-at $254 \mathrm{~nm}$ (Agilent Technologies) and a $1260 \mathrm{RI}$-detector-G1362A—at $30{ }^{\circ} \mathrm{C}$ (Agilent Technologies), THF as the mobile phase (flow rate $1 \mathrm{~mL} \cdot \mathrm{min}^{-1}$ ) on a SDV column set from PSS (Polymer Standard Service (PSS), Mainz, Germany) (SDV $10^{3}$, SDV $10^{5}$, SDV $10^{6}$ ). Calibration was carried out using PS standards (from PSS). SEC-MALLS (Multi-Angle Laser Light Scattering) was performed using a light scattering detector SLD7000-BI-MwA at $633 \mathrm{~nm}$ (Brookhaven Instruments, Holtsville, NY, USA). For data acquisition and evaluation of the measurements, PSS WinGPC ${ }^{\circledR}$ UniChrom 8.2 was used. Thermogravimetric analysis (TGA) was measured using a Mettler Toledo TGA-2 using a heating rate of $10 \mathrm{~K} \cdot \mathrm{min}^{-1}$ under air or nitrogen. Thermal treatment of the PMAPOSS-containing cellulose substrates and PMAPOSS homopolymers were performed in an Astro graphite furnace (Thermal Technology Inc., Santa Rosa, CA, USA) under nitrogen atmosphere. The sample was heated up to $1600{ }^{\circ} \mathrm{C}$ with the rate of $10 \mathrm{~K} \cdot \mathrm{min}^{-1}$, and hold at $1600{ }^{\circ} \mathrm{C}$ for $10 \mathrm{~min}$. Finally, the samples were cooled to room temperature with the rate of $10 \mathrm{~K} \cdot \mathrm{min}^{-1}$. The static contact angle (CA) was measured using the sessile-drop method with a Contact Angle System DataPhyciscs OCA 15 EC (Filderstadt, Germany) using $2 \mu \mathrm{L}$ droplets of deionized water. The measurements were conducted in a controlled climatic chamber at $T=23 \pm 2{ }^{\circ} \mathrm{C}$ and at a relative humidity of $40 \%$. CAs were determined geometrically using the SCA20 software by aligning a tangent from the surficial contact point along the droplets surface in the droplet profile. Scanning electron microscopy (SEM) and energy dispersive X-ray spectroscopy (EDS) measurements were performed on a FEI/Philips XL30 FEG (Philips, Amsterdam, The Netherlands) at an operating voltage of 5-30 kV. The SEM samples were coated with approx. $4 \mathrm{~nm} \mathrm{Cr}$ or $8 \mathrm{~nm}$ Au using a Quorum Q300T D Sputter Coater (Lewes, UK). Powder X-ray diffraction measurements were performed on a STADIP (Stoe \& Cie GmbH, Darmstadt, Germany). All measurements were carried out on flat sample holders in transmission geometry $\left(20^{\circ}-90^{\circ} / 2 \theta, \lambda=1.54060 \AA, \mathrm{Ge}[111]\right.$-monochromator $)$ and a Mythen1K (Dectris, Baden, Switzerland) detector. Micro Raman spectra were recorded with a Horiba HR800 micro Raman spectrometer (Horiba JobinYvon, Bensheim, Germany) equipped with an Ar laser $(514.5 \mathrm{~nm})$. The measurements were performed by using a grating of $600 \mathrm{~g} \cdot \mathrm{mm}^{-1}$ and a confocal microscope (magnification $100 \times$ NA 0.5) with a $100 \mu \mathrm{m}$ aperture, giving a resolution of 2 to $4 \mu \mathrm{m}$. The laser power $(20 \mathrm{~mW})$ was attenuated by using neutral density filters to avoid heat-induced sample damage; thus the power on the sample was in the range of $0.2 \mathrm{~mW}$. Infrared (IR) spectroscopy was performed on a spectrum One instrument (Perkin-Elmer, Waltham, MA, USA) in attenuated total reflection (ATR) mode. IR spectra were recorded in a range from 4000 to $650 \mathrm{~cm}^{-1}$. The measured spectra were automatically background- and baseline-corrected.

\subsection{Paper Functionalization with ATRP Initiator}

The filter discs were placed in a Schlenk tube, dried in vacuum and in an atmosphere of argon dry toluene (30 mL) and 3-(2-bromoisobutyrate)propyl trichlorosilane (1 g; $2.92 \mathrm{mmol})$ were added. 
After stirring at $60^{\circ} \mathrm{C}$ for $24 \mathrm{~h}$, the papers were extracted with $\mathrm{THF}, \mathrm{MeOH}$, and water to remove the physisorbed initiator and dried in vacuum.

\subsection{Surface-Initiated Polymerization of MAPOSS from Cellulose Substrate}

The functionalized paper discs were placed in a Schlenk tube, dried in vacuum, and refilled with argon. After the addition of anisole ( $15 \mathrm{~mL})$, MAPOSS ( $2000 \mathrm{mg}, 2.12 \mathrm{mmol})$, and 2 bromo-iso-butyric tert-butylester $(t \mathrm{Bbib})(7.5 \mu \mathrm{L}, 0.04 \mathrm{mmol})$, the solution was heated to $60{ }^{\circ} \mathrm{C}$. The polymerization was initiated by adding a solution of [Cu $\mathrm{I}(\mathrm{PMDETA}) \mathrm{Cl}](0.2 \mathrm{M}, 0.2 \mathrm{~mL}, 0.04 \mathrm{mmol}$ in anisole). The polymerization solution was precipitated in $\mathrm{MeOH}$ after $48 \mathrm{~h}$ and the papers were washed several times with THF and $\mathrm{MeOH}$, followed by drying in vacuo. The precipitated polymer was collected by filtration, dried under reduced pressure, and characterized by SEC. SEC (vs. PS): $M_{n}: 4900 \mathrm{~g} / \mathrm{mol}$, $M_{w}: 5500 \mathrm{~g} / \mathrm{mol}, \boxminus: 1.12$.

\section{Results and Discussion}

\subsection{Functionalization of Cellulose-Based Substrates with PMAPOSS}

For surface-initiated ATRP (SI-ATRP) of (3-methacryloxypropyl)heptaisobutyl-T8-silsesquioxane (MAPOSS) 2 from the surface of cellulose-based substrates, the cellulose substrates were functionalized with 3-(2-bromoisobutyrate)propyl trichlorosilane 1 as ATRP-initiator as given in Scheme 1 (cf. the Experimental Section).

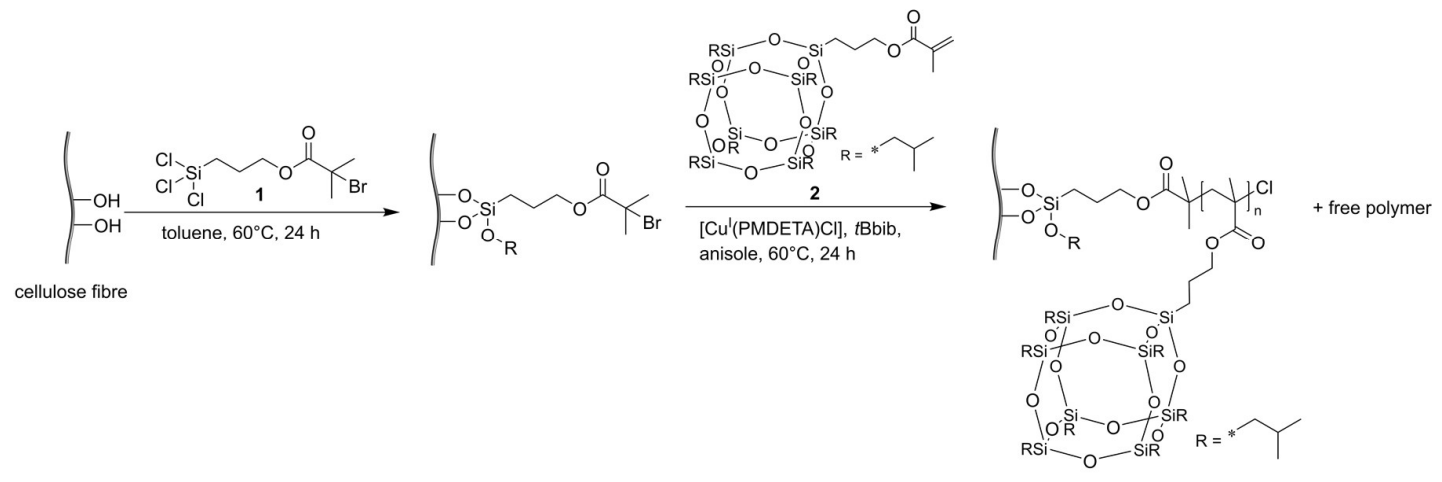

Scheme 1. Surface-initiated atom transfer radical polymerization (ATRP) of (3-methacryloxypropyl) heptaisobutyl-T8-silsesquioxane (MAPOSS) 2 from the surface of a cellulose-based substrate after functionalization with the ATRP-initiator 1.

After thorough rinsing with methanol $(\mathrm{MeOH})$, water and tetrahydrofuran (THF), the initiator-decorated cellulose substrates were subjected to an ATRP system for the grafting-from polymerization of MAPOSS monomer 2. In addition to the formation of immobilized PMAPOSS, free ATRP-initiator, i.e., 2-bromo-iso-butyric tert-butylester ( $t$ Bbib) was added to the SI-ATRP in order to investigate both the molar masses and dispersity index values, $Ð$, for immobilized and free PMAPOSS. As previously reported, the length of surface-immobilized polymer chains and free polymer chains could be directly compared as a first approximation [56,57]. After the ATRP reaction, the PMAPOSS-functionalized cellulose substrates were thoroughly washed with THF and methanol in order to remove free PMAPOSS and residual compounds from the ATRP system. The molar mass of PMAPOSS obtained by polymerization in solution was determined to be $4900 \mathrm{~g} \cdot \mathrm{mol}^{-1}\left(M_{n}\right)$ featuring a dispersity index value of $Đ=1.12$ as determined by size-exclusion chromatography (SEC) vs. polystyrene (PS) standards (Figure S1). For comparison within this study and for use as a blank sample, PMAPOSS homopolymers were also synthesized by means of living anionic polymerization (cf. experimental section). The blank sample featured a molar mass of $8100 \mathrm{~g} \cdot \mathrm{mol}^{-1}$ $\left(M_{n}\right)$ and a dispersity index value of $\boxminus=1.04$ as determined by SEC vs. PS standards. As polymers can significantly differ with respect to their hydrodynamic volume compared to PS standards, SEC 
measurements equipped with a multi-angle laser light scattering (MALLS) detector was performed in order to determine the absolute molar mass of the PMAPOSS samples. After determining the differential refractive index of PMAPOSS to be $d n / d c=0.0593$, the absolute molar mass was determined to be $12,500 \mathrm{~g} \cdot \mathrm{mol}^{-1}$ (compared to $8100 \mathrm{~g} \cdot \mathrm{mol}^{-1}$ for the blank sample). The molar mass distributions of synthesized PMAPOSS are shown in Figure S2. This finding confirmed that in general the molar mass of PMAPOSS is underestimated for SEC measurements using PS as standards compared the absolute molar mass. To prove the successful functionalization of the cellulose substrate with PMAPOSS, ATR FT-IR spectroscopy was carried out. For this purpose, IR spectra of a blank cellulose substrate, a substrate featuring the ATRP-initiator, and a cellulose substrate of polymerizing MAPOSS monomer were compared (Figure 1). As shown in these spectra, all samples featured nearly the same signals such as the $\mathrm{OH}$-stretching vibration observed between 3000 and $3600 \mathrm{~cm}^{-1}$, the symmetric and asymmetric stretching vibration of the $\mathrm{CH}_{2}$ and $\mathrm{CH}_{3}$ groups at approximately $2800-3000 \mathrm{~cm}^{-1}$ and between 900 and $1200 \mathrm{~cm}^{-1}$ and the specific $\mathrm{C}-\mathrm{O}$ vibration band at $1035 \mathrm{~cm}^{-1}$. While the IR signals of $\mathrm{CH}$ and $\mathrm{OH}$ at approximately $1300-1500 \mathrm{~cm}^{-1}$ were found to be similar for all three investigated samples, the vibrational band at $1732 \mathrm{~cm}^{-1}$, which can be assigned to the $\mathrm{C}=\mathrm{O}$ vibration of the ATRP-initiator and PMAPOSS, was found only for the modified cellulose substrates, clearly evidencing their successful functionalization. Compared to the IR spectrum of the PMAPOSS blank sample (Figure S3), no additional signals for the polymer-modified substrate could be observed, which could be additionally used for PMAPOSS identification. Therefore, additional contact angle (CA) measurements were performed.

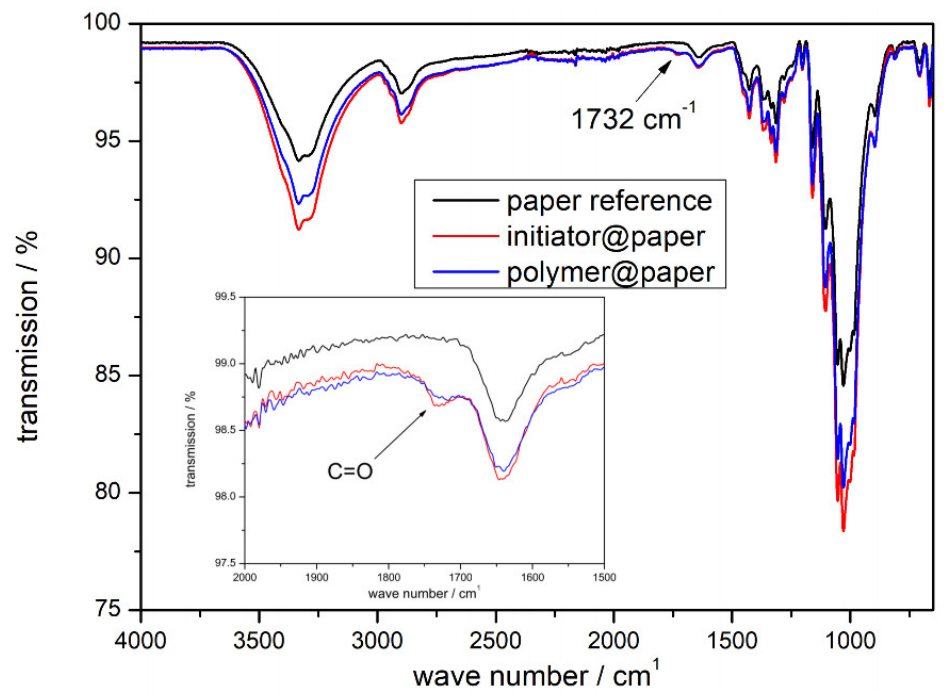

Figure 1. Infrared spectra of a reference cellulose substrate (black line), an ATRP-initiator functionalized substrate (red line) and a PMAPOSS-modified substrate (blue line) and additional zoom-in between 1500 and $2000 \mathrm{~cm}^{-1}$.

CA measurements were carried out to prove the successful functionalization and to determine the surface wettability of the substrates prior to and after ATRP-initiator functionalization and PMAPOSS functionalization, respectively $[58,59]$. The corresponding CA measurements of a reference cellulose substrate, a substrate functionalized with the ATRP-initiator and a PMAPOSS-containing substrate were performed in a climate chamber using droplets of deionized water at 7 different positions (cf. experimental section). The corresponding images are given in Figure 2, while the determined contact angles are compiled in Table 1 . As can be concluded from these results, the reference cellulose substrate revealed a hydrophilic character with small contact angles of around $5^{\circ} \pm 1^{\circ}$ and the water drops being soaked into the substrate within $5 \mathrm{~s}$. Unlike the reference substrate, the sample functionalized with trichlorosilane ATRP-initiator exhibited contact angles of $121^{\circ} \pm 7^{\circ}$, thus a highly hydrophobic character. This finding confirmed the successful functionalization with the hydrophobic 
ATRP-initiator $[45,60]$. It seems that the subsequent SI-ATRP of MAPOSS leads to a further slight increase of the contact angle to $131^{\circ} \pm 3^{\circ}$, reflecting the more hydrophobic character of the isobutyl moieties of the PMAPOSS-modified substrate.

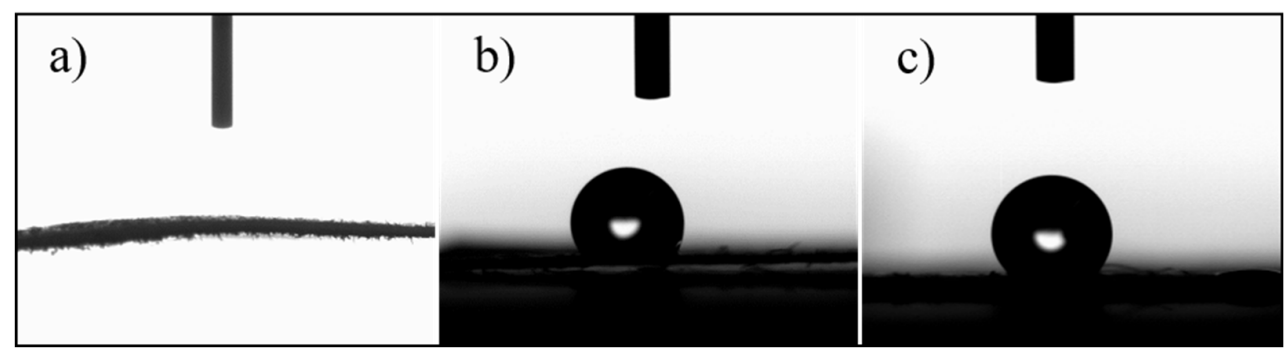

Figure 2. Contact angles obtained for (a) cellulose substrate reference, (b) ATRP-initiator functionalized paper substrate, and (c) PMAPOSS-functionalized substrate.

Table 1. Summarized contact angles for cellulose substrate reference, a substrate with ATRP initiator and PMAPOSS-functionalized substrates.

\begin{tabular}{cc}
\hline Sample & CA/ $^{\circ}$ \\
\hline Cellulose Substrate & $5 \pm 1^{\text {a }}$ \\
ATRP-Initiator@Cellulose & $121 \pm 7$ \\
PMAPOSS@Cellulose & $131 \pm 3$ \\
\hline a Water drop was absorbed from cellulose reference within $5 \mathrm{s.}$
\end{tabular}

\subsection{Ceramisation of the PMAPOSS-Modified Cellulose Substrates}

Thermogravimetric analysis (TGA) of the pristine cellulose substrate and both PMAPOSS-modified substrates revealed a slightly different degradation process under air and nitrogen atmosphere up to $600^{\circ} \mathrm{C}$ as displayed in Figure 3 and Figures S4 and S5. Additional TGA measurements of PMAPOSS under air and nitrogen atmosphere are given as Figure S6.

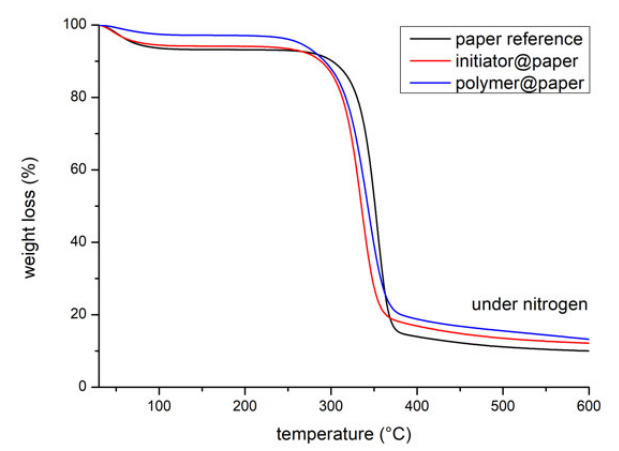

(a)

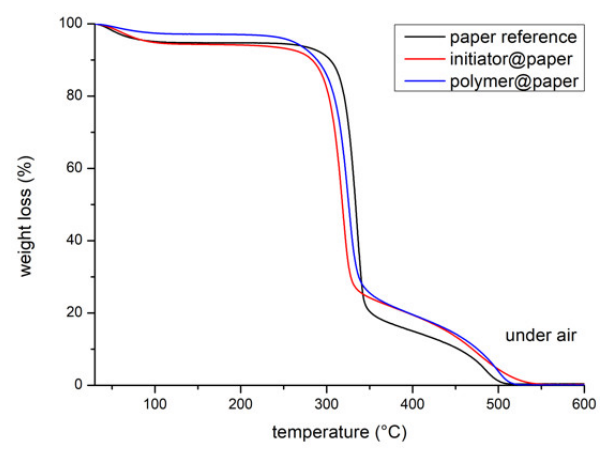

(b)

Figure 3. Thermograms of the cellulose substrate reference after TGA (black line), initiator functionalized paper (red line), and PMAPOSS functionalized paper substrate (blue line). TGA measurements were performed with a heat rate of $10 \mathrm{~K} \cdot \mathrm{min}^{-1}$ in a nitrogen atmosphere (a) and under air (b) up to $600^{\circ} \mathrm{C}$.

Moreover, thermal treatment under air atmosphere lead to an almost complete combustion of the cellulose substrates, while the thermal treatment under nitrogen atmosphere lead to a char yield of $\sim 10 \mathrm{wt} . \%$. Although the weight loss for all three substrates was almost equal for each atmosphere, the degradation of the reference substrate revealed a slightly different pattern in contrast to the polymer-modified cellulose-based substrates. This gives another hint for the successful functionalization with the ATRP-initiator and PMAPOSS. The degradation of the reference substrate 
started at $270{ }^{\circ} \mathrm{C}$ both under air or nitrogen atmosphere. Compared to this, the PMAPOSS-modified substrates revealed a degradation temperature at approximately $240{ }^{\circ} \mathrm{C}$. The results on TGA are summarized in Table 2.

Table 2. Data on TGA for investigated cellulose substrates: Residue by TGA under nitrogen and air atmosphere for reference and functionalized cellulose substrates.

\begin{tabular}{ccc}
\hline Sample & Residue (air) $^{\mathbf{a}}$ & Residue $^{\left(\mathbf{N}_{\mathbf{2}} \mathbf{~}^{\mathbf{b}}\right.}$ \\
\hline Cellulose Substrate & $0.4 \mathrm{wt} . \%$ & $10.2 \mathrm{wt} . \%$ \\
ATRP-Initiator@Cellulose & $0.6 \mathrm{wt} \%$ & $12.4 \mathrm{wt} . \%$ \\
PMAPOSS@Cellulose & $0.4 \mathrm{wt} . \%$ & $13.7 \mathrm{wt} \%$ \\
\hline
\end{tabular}

a Weight residue in \% analysed by TGA up to $600{ }^{\circ} \mathrm{C}$ under air. ${ }^{b}$ Weight residue in $\%$ analysed by TGA up to $600{ }^{\circ} \mathrm{C}$ in nitrogen atmosphere.

As pointed out in the introduction, paper-derived ceramics can be designed with preservation of the biotemplated cellulose fibre structure. In order to investigate the morphology of the herein investigated and obtained materials after thermal treatment, ATR IR spectroscopy, scanning electron microscopy (SEM) measurements in combination with energy dispersive $\mathrm{X}$-ray spectroscopy (EDS) were performed.

First, the thermally treated cellulose substrates were investigated by ATR IR spectroscopy (Figures 4 and 5). Starting with the IR spectra of the thermal treated paper substrate under air, the initiator and polymer functionalized substrate reveal an asymmetric stretching vibration of $\mathrm{Si}-\mathrm{O}-\mathrm{Si}$ bridging sequences at 1030 or $1022 \mathrm{~cm}^{-1}$, which can also be obtained for the PMAPOSS reference sample at $1055 \mathrm{~cm}^{-1}$. At $800 \mathrm{~cm}^{-1}$, a symmetric stretching vibration of Si-O-Si bonds was observed both for the modified cellulose substrates and for the PMAPOSS reference sample [61,62]. For the PMAPOSS-modified cellulose substrate a band at $1590 \mathrm{~cm}^{-1}$ could be observed, which can be assigned to $\mathrm{sp}^{2}$-hybridized carbon $(\mathrm{C}=\mathrm{C})$.

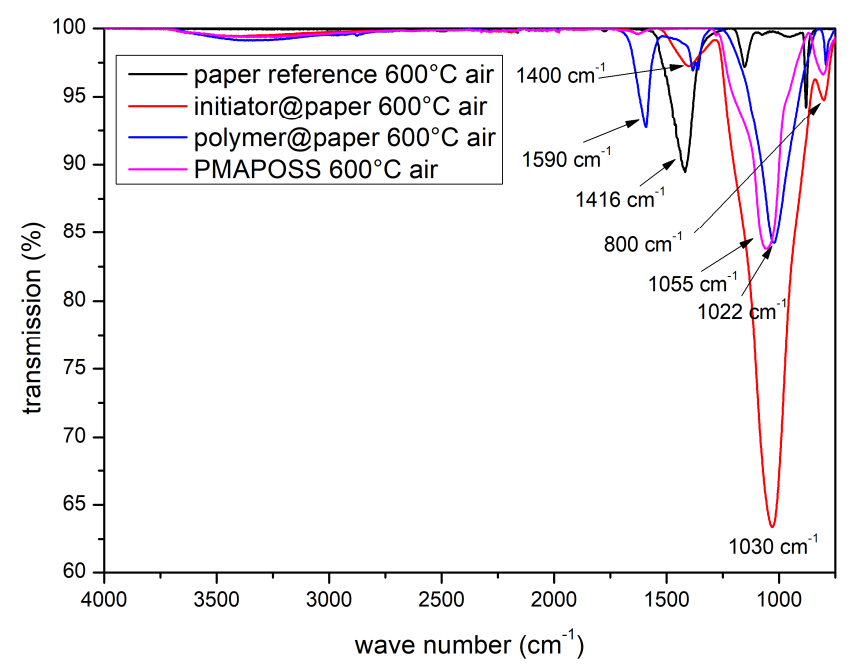

Figure 4. Infrared spectra of a cellulose reference substrate (black line), an ATRP-initiator functionalized cellulose substrate (red line), a PMAPOSS-modified substrate (blue line), and PMAPOSS (blank sample) after thermal treatment up to $600{ }^{\circ} \mathrm{C}$ under air. 


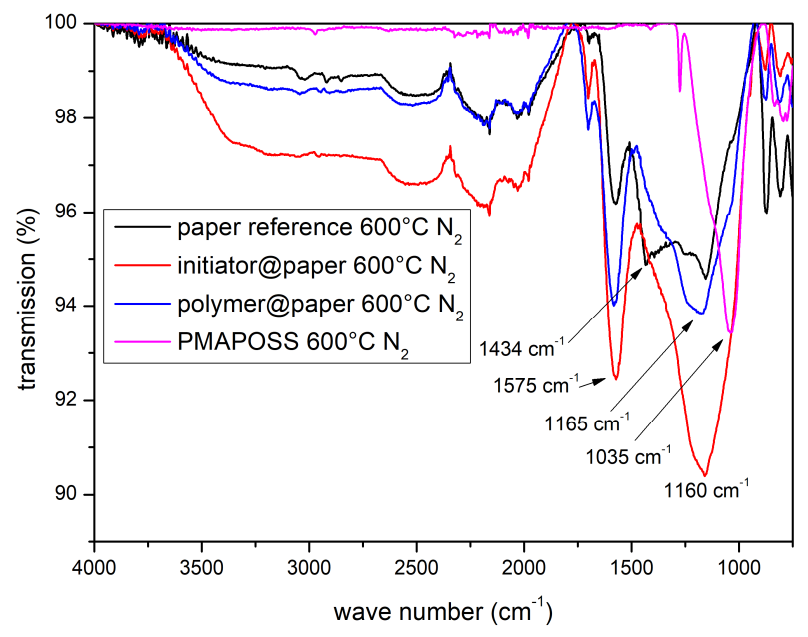

Figure 5. Infrared spectra of a cellulose reference substrate (black line), an ATRP-initiator functionalized cellulose substrate (red line), a PMAPOSS-modified substrate (blue line), and PMAPOSS (reference sample) after thermal treatment up to $600{ }^{\circ} \mathrm{C}$ under nitrogen atmosphere.

In case of the thermally treated cellulose substrate under nitrogen atmosphere, IR spectra for all investigated cellulose substrates revealed same transmission band signals between 1770 and $4000 \mathrm{~cm}^{-1}$. $\mathrm{C}=\mathrm{O}$ stretching vibrations at $1575 \mathrm{~cm}^{-1}$ and $\mathrm{C}-\mathrm{O}-\mathrm{C}$ stretching vibrations at around $1160 \mathrm{~cm}^{-1}$ were found to be similar for all three thermally treated cellulose substrates. At $1434 \mathrm{~cm}^{-1} \mathrm{a} \mathrm{CH} / \mathrm{OH}$ bending vibration occurs for the paper reference substrate, while the only vibration for the PMAPOSS reference at around $1035 \mathrm{~cm}^{-1}$ may correspond to $\mathrm{Si}-\mathrm{O}-\mathrm{Si}$ or $\mathrm{Si}-\mathrm{N}$ groups. IR spectra of the thermal treated, PMAPOSS modified paper substrate up to $1600{ }^{\circ} \mathrm{C}$ (Figure S7) revealed only two significant bands at 1375 and $845 \mathrm{~cm}^{-1}$, which could be assigned to $\mathrm{C}-\mathrm{C}$ and $\mathrm{SiC}$ vibrations, respectively [61].

In brief, the IR spectra of thermally-treated modified cellulose substrates up to $600{ }^{\circ} \mathrm{C}$ under air were significantly different, mainly showing $\mathrm{Si}-\mathrm{O}-\mathrm{Si}$ groups, compared to the thermally-treated reference substrates. Compared to these findings, in nitrogen atmosphere, only slight differences could be identified for samples treated at a temperature of $600^{\circ} \mathrm{C}$.

The SEM images of a pristine reference cellulose substrate and PMAPOSS-modified substrate are given as Figures S8-S11 along with the EDS spectra. It can be concluded from these SEM photographs that the ATRP conditions, i.e., solvent treatment and washing steps, did not harm the cellulose substrates and therefore no influence on the entire cellulose fibre structure could be observed. Furthermore, silicon signals could be observed after PMAPOSS immobilization in the corresponding EDS spectra, again proving the successful SI-ATRP of MAPOSS. The SEM images after thermal treatment under different atmospheres, i.e., air or nitrogen atmosphere, are given in Figure 6. The residual material of the cellulose substrate thermally treated up to $600{ }^{\circ} \mathrm{C}$ under air (Figure 6a) revealed an almost complete loss of the fibre morphology, which was expected according to the almost complete decomposition of the cellulose substrate (cf. TGA measurements Figure 3 and Table 2). Compared to this, thermally treated samples up to $600{ }^{\circ} \mathrm{C}$ under nitrogen atmosphere (Figure $6 \mathrm{~b}$ ) occurred with preservation of the cellulose fibre structure. The shrinkage of the pristine fibres (cf. Figure S8) could be estimated to be $10 \%-20 \%$ at a temperature of $600{ }^{\circ} \mathrm{C}$. Interestingly, similar results for the shrinkage of approximately $20 \%-30 \%$ were found for thermally treated and modified cellulose substrate up to $1600{ }^{\circ} \mathrm{C}$ under nitrogen. Moreover, SEM images of the PMAPOSS-modified cellulose substrates featured spherical domains with an average diameter of around $2 \mu \mathrm{m}$ (Figure $6 \mathrm{c}$ ). Compared to findings for the cellulose substrates treated at $600{ }^{\circ} \mathrm{C}$ (Figure S12a,b), the silicon signal for samples treated at $1600^{\circ} \mathrm{C}$ increased as can be concluded from the corresponding EDS spectrum (Figure S12c). EDS recorded exclusively from the spherical domains revealed an intensive silicon signal (besides the chromium signal, which was used as sputter-coating material for SEM measurements) (Figure S12d). Noteworthy, the silicon-based materials seem to be part of the thermally treated cellulose 
interlayer, which is different compared to findings for infiltration experiments [63]. Additional XRD measurements of the biotemplated cellulose substrate revealed Bragg reflections, which can be assigned to $\beta$-SiC containing high densities of stacking faults (Figure S13) [64], proving the feasibility of the herein investigated functionalization approach for the preparation of porous silicon-containing ceramic materials with hierarchically ordered domains. Complementary Raman spectroscopy investigations of the thermally treated materials (Figure S14) revealed the presence of highly disordered $\mathrm{sp}^{2}$-hybridized carbon, which increased slightly its crystallinity upon thermal treatment at $1600{ }^{\circ} \mathrm{C}$. These findings are in very good agreement with the IR signals described above and with findings from other studies $[65,66]$.

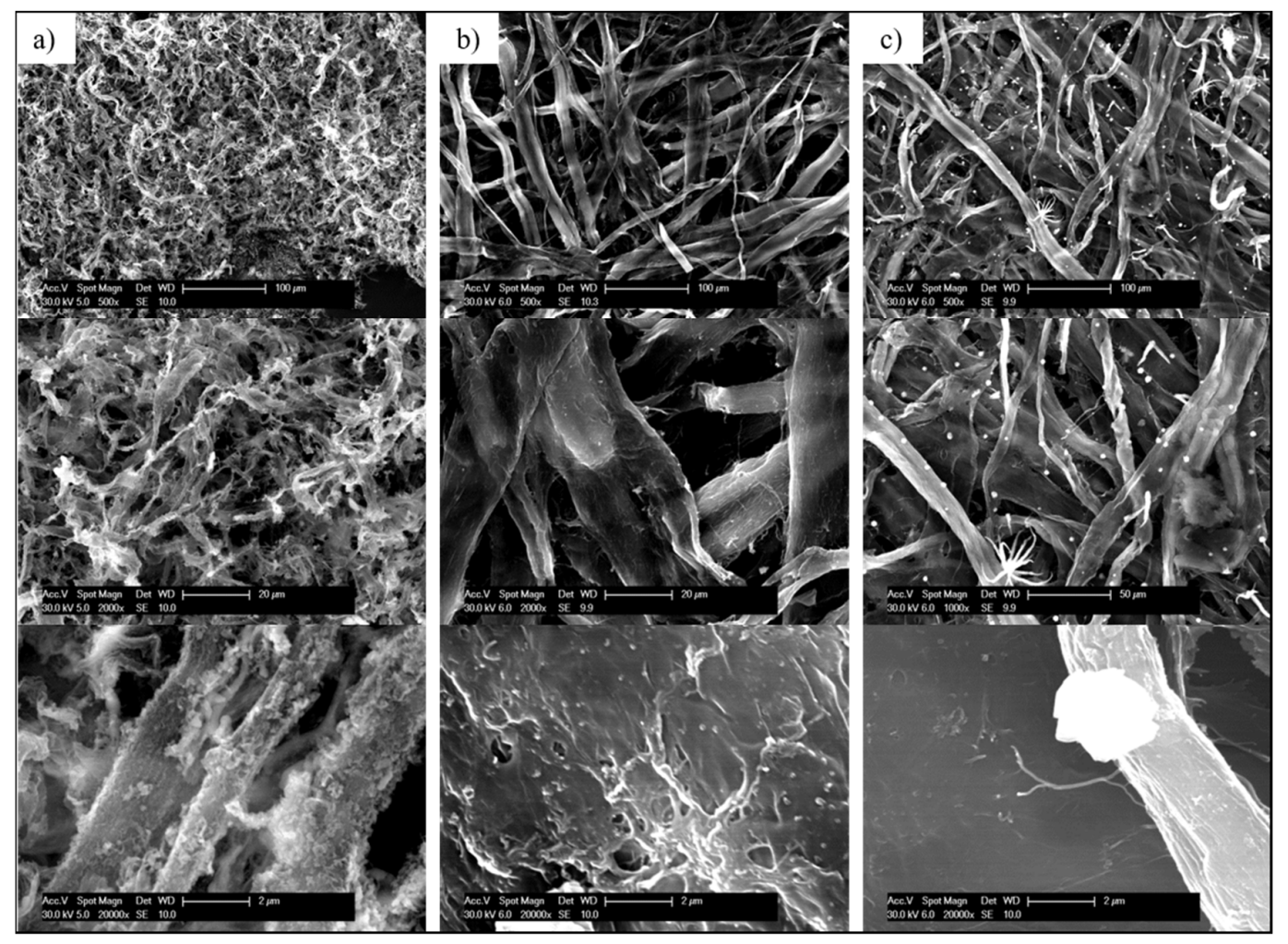

Figure 6. SEM images of thermally treated PMAPOSS-modified cellulose substrates: after treatment up to $600{ }^{\circ} \mathrm{C}$ under air (a); after thermal treatment up to $600{ }^{\circ} \mathrm{C}$ under nitrogen (b); and after thermal treatment up to $1600{ }^{\circ} \mathrm{C}$ under nitrogen atmosphere (c).

Summarizing the morphological characterizations thermally treated PMAPOSS-modified cellulose substrates revealed almost complete decomposition of the fibre structure, while for the same substrates treated under nitrogen, the fibre morphology was preserved additionally featuring silicon-containing spherical domains at the cellulose-templated fibre structure.

\section{Conclusions}

In summary, cellulose-based substrates were modified with a POSS-containing polymethacrylate (PMAPOSS) by means of surface-initiated atom transfer radical polymerization (SI-ATRP) after functionalization with an ATRP initiator. Change of the surface wettability to a hydrophobic polymer-modified cellulose-based substrate was proven by contact angle measurements. The cellulose materials featuring PMAPOSS as preceramic polymer could be used as bio-template for the preparation of carbonaceous fibres having spherical silicon-containing domains. Interestingly, these spherical domains at the surface of the carbon fibres were obtained after thermal treatment at $1600{ }^{\circ} \mathrm{C}$ under a nitrogen atmosphere containing a high amount of silicon as determined by SEM and EDS measurements. We envisage this convenient functionalization of biomorphic templates with tailored 
preceramic polymers to be a feasible platform for the preparation of ceramic materials upon controlling the porosity, which will enable a wide range of materials as lightweight components and hybrid membranes. Moreover, material compositions based on cellulose-derived carbon decorated with ceramic (nano)particles may be of high relevance for energy storage applications, e.g., as electrode materials in Li ion batteries or (super)capacitors. Especially, ceramic papers may be interesting for the use at high temperatures and in hostile environments, due to their remarkable robustness.

Supplementary Materials: Additional materials and methods for anionic polymerization of MAPOSS, additional SEC measurements, additional IR spectra, additional TGA, SEM photographs, EDX spectra, XRD patterns, and Raman spectra are available online at http://www.mdpi.com/2079-6412/8/12/446/s1.

Author Contributions: Conceptualization, C.R. and M.G.; Methodology, C.R., S.V., N.H., E.I. and K.H.; Writing-Original Draft Preparation, C.R. and M.G.; Writing-Review and Editing, C.R., E.I. and M.G.; Visualization, C.R. and M.G.; Supervision, M.G.; Project Administration, C.R. and M.G.; Funding Acquisition, M.G.

Funding: This research was supported by the DFG project GA2169/7-1 in association with the DFG-funded consortium for advanced paper research (DFG-PAK 962/1) at TU Darmstadt.

Acknowledgments: The authors thank M. Biesalski and his group (Macromolecular Chemistry and Paper Chemistry Department, TU Darmstadt) for analytical support, Cong Zhou for help with thermal treatment of the polymer-modified substrates at $1600{ }^{\circ} \mathrm{C}$, and Felix Rosenburg for Raman spectroscopy measurements. S.V. thanks the Evangelisches Studienwerk Villigst for partial financial support of this work.

Conflicts of Interest: The authors declare no conflict of interests.

\section{References}

1. Christodoulou, L.; Venables, J.D. Multifunctional material systems: The first generation. JOM 2003, 55, 39-45. [CrossRef]

2. Dumanli, A.G.; Savin, T. Recent advances in the biomimicry of structural colours. Chem. Soc. Rev. 2016, 45, 6698-6724. [CrossRef] [PubMed]

3. Davis, M.E. Ordered porous materials for emerging applications. Nature 2002, 417, 813-821. [CrossRef] [PubMed]

4. Whitesides, G.M. Nanoscience, nanotechnology, and chemistry. Small 2005, 1, 172-179. [CrossRef] [PubMed]

5. Burda, C.; Chen, X.; Narayanan, R.; El-Sayed, M.A. Chemistry and properties of nanocrystals of different shapes. Chem. Rev. 2005, 105, 1025-1102. [CrossRef] [PubMed]

6. Piao, Y.; Burns, A.; Kim, J.; Wiesner, U.; Hyeon, T. Designed fabrication of silica-based nanostructured particle systems for nanomedicine applications. Adv. Funct. Mater. 2008, 18, 3745-3758. [CrossRef]

7. Zhao, Y.; Jiang, L. Hollow micro/nanomaterials with multilevel interior structures. Adv. Mater. 2009, 21, 3621-3638. [CrossRef]

8. Talapin, D.V.; Lee, J.S.; Kovalenko, M.V.; Shevchenko, E.V. Prospects of colloidal nanocrystals for electronic and optoelectronic applications. Chem. Rev. 2010, 110, 389-458. [CrossRef] [PubMed]

9. Schäfer, C.G.; Vowinkel, S.; Hellmann, G.P.; Herdt, T.; Contiu, C.; Schneider, J.J.; Gallei, M. A polymer based and template-directed approach towards functional multidimensional microstructured organic/inorganic hybrid materials. J. Mater. Chem. C 2014, 2, 7960-7975. [CrossRef]

10. Schüth, F.; Schmidt, W. Microporous and mesoporous materials. Adv. Mater. 2002, 14, 629-638. [CrossRef]

11. Stein, A. Advances in microporous and mesoporous solids-highlights of recent progress. Adv. Mater. 2003, 15, 763-775. [CrossRef]

12. Thomas, A.; Goettmann, F.; Antonietti, M. Hard templates for soft materials: Creating nanostructured organic materials. Chem. Mater. 2008, 20, 738-755. [CrossRef]

13. Sahoo, J.K.; Tahir, M.N.; Yella, A.; Schladt, T.D.; Pfeiffer, S.; Nakhjavan, B.; Mugnaioli, E.; Kolb, U.; Tremel, W. From single molecules to nanoscopically structured materials: Self-Assembly of metal chalcogenide/metal oxide nanostructures based on the degree of pearson hardness. Chem. Mater. 2011, 23, 3534-3539. [CrossRef]

14. Joshi, R.K.; Schneider, J.J. Assembly of one dimensional inorganic nanostructures into functional 2D and 3D architectures. Synthesis, arrangement and functionality. Chem. Soc. Rev. 2012, 41, 5285-5312. [CrossRef] [PubMed]

15. Kaur, S.; Gallei, M.; Ionescu, E. Polymer-ceramic nanohybrid materials. In Organic-Inorganic Hybrid Nanomaterials; Kalia, S., Haldorai, Y., Eds.; Springer: Basel, Switzerland, 2015; Volume 267, pp. 143-185. 
16. Mera, G.; Gallei, M.; Bernard, S.; Ionescu, E. Ceramic nanocomposites from tailor-made preceramic polymers. Nanomaterials 2015, 5, 468-540. [CrossRef] [PubMed]

17. Vowinkel, S.; Schäfer, C.G.; Cherkashinin, G.; Fasel, C.; Roth, F.; Liu, N.; Dietz, C.; Ionescu, E.; Gallei, M. 3D-ordered carbon materials by melt-shear organization for tailor-made hybrid core-shell polymer particle architectures. J. Mater. Chem. C 2016, 4, 3976-3986. [CrossRef]

18. Gallei, M. Functional polymer opals and porous materials by shear-induced assembly of tailor-made particles. Macromol. Rapid Commun. 2018, 39, 1700648. [CrossRef]

19. Mera, G.; Ionescu, E. Silicon-containing preceramic polymers. In Encyclopedia of Polymer Science and Technology, 3rd ed.; Mark, H.F., Ed.; John Wiley \& Sons, Inc.: Hoboken, NY, USA, 2013. [CrossRef]

20. Colombo, P.; Mera, G.; Riedel, R.; Sorarù, G.D. Polymer-derived ceramics: 40 years of research and innovation in advanced ceramics. J. Am. Ceram. Soc. 2010, 93, 1805-1837. [CrossRef]

21. Mera, G.; Riedel, R. Organosilicon-based polymers as precursors for ceramics. In Polymer Derived Ceramics: From Nanostructure to Applications; Colombo, P., Ed.; DEStech Publications Inc.: Lancaster, PA, USA, 2010; pp. 51-89.

22. Ionescu, E.; Kleebe, H.J.; Riedel, R. Silicon-containing polymer-derived ceramic nanocomposites (PDC-NCs): Preparative approaches and properties. Chem. Soc. Rev. 2012, 41, 5032-5052. [CrossRef]

23. Riedel, R.; Mera, G.; Hauser, R.; Klonczynski, A. Silicon-based polymer-derived ceramics: Synthesis properties and applications-A review dedicated to Prof. Dr. Fritz Aldinger on the occasion of his 65th birthday. J. Ceram. Soc. Jpn. 2006, 114, 425-444. [CrossRef]

24. Stabler, C.; Ionescu, E.; Graczyk-Zajac, M.; Gonzalo-Juan, I.; Riedel, R. Silicon oxycarbide glasses and glass-ceramics: "All-Rounder" materials for advanced structural and functional applications. J. Am. Ceram. Soc. 2018, 101, 4817-4856. [CrossRef]

25. Abe, K.; Kotera, K.; Suzuki, K.; Citterio, D. Inkjet-printed paperfluidic immuno-chemical sensing device. Anal. Bioanal.Chem. 2010, 398, 885-893. [CrossRef] [PubMed]

26. Leung, V.; Shehata, A.A.M.; Filipe, C.D.M.; Pelton, R. Streaming potential sensing in paper-based microfluidic channels. Colloids Surf. A 2010, 364, 16-18. [CrossRef]

27. Olsson, H.; Nyström, G.; Strømme, M.; Sjödin, M.; Nyholm, L. Cycling stability and self-protective properties of a paper-based polypyrrole energy storage device. Electrochem. Commun. 2011, 13, 869-871. [CrossRef]

28. Tobjörk, D.; Österbacka, R. Paper electronics. Adv. Mater. 2011, 23, 1935-1961. [CrossRef]

29. Schöttner, S.; Schaffrath, H.J.; Gallei, M. Poly(2-hydroxyethyl methacrylate)-based amphiphilic block copolymers for high water flux membranes and ceramic templates. Macromolecules 2016, 49, 7286-7295. [CrossRef]

30. Sun, W.; Zhou, S.; You, B.; Wu, L. A facile method for the fabrication of superhydrophobic films with multiresponsive and reversibly tunable wettability. J. Mater. Chem. A 2013, 1, 3146-3154. [CrossRef]

31. Janko, M.; Jocher, M.; Boehm, A.; Babel, L.; Bump, S.; Biesalski, M.; Meckel, T.; Stark, R.W. Cross-linking cellulosic fibers with photoreactive polymers: Visualization with confocal Raman and fluorescence microscopy. Biomacromolecules 2015, 16, 2179-2187. [CrossRef]

32. Sieber, H.; Hoffmann, C.; Kaindl, A.; Greil, P. Biomorphic cellular ceramics. Adv. Eng. Mater. 2000, 2, $105-109$. [CrossRef]

33. Vyshnyakova, K.; Yushin, G.; Pereselentseva, L.; Gogotsi, Y. Formation of porous SiC ceramics by pyrolysis of wood impregnated with silica. Int. J. Appl. Ceram. Technol. 2006, 3, 485-490. [CrossRef]

34. Ghanem, H.; Gerhard, H.; Popovska, N. Paper derived SiC-Si3N4 ceramics for high temperature applications. Ceram. Int. 2009, 35, 1021-1026. [CrossRef]

35. Sieber, H.; Zollfrank, C.; Popovska, N.; Almeida, D.; Gerhard, H. Gas phase processing of porous, biomorphous TiC-ceramics. Key Eng. Mater. 2004, 264-268, 2227-2230. [CrossRef]

36. Fan, T.; Li, X.; Ding, J.; Zhang, D.; Guo, Q. Synthesis of biomorphic $\mathrm{Al}_{2} \mathrm{O}_{3}$ based on natural plant templates and assembly of Ag nanoparticles controlled within the nanopores. Microporous Mesoporous Mater. 2008, 108, 204-212. [CrossRef]

37. Zampieri, A.; Sieber, H.; Selvam, T.; Mabande, G.T.P.; Schwieger, W.; Scheffler, F.; Scheffler, M.; Greil, P. Biomorphic cellular $\mathrm{SiSiC} /$ zeolite ceramic composites: From rattan palm to bioinspired structured monoliths for catalysis and sorption. Adv. Mater. 2005, 17, 344-349. [CrossRef]

38. Travitzky, N.; Windsheimer, H.; Fey, T.; Greil, P. Preceramic paper-derived ceramics. J. Am. Cer. Soc. 2008, 91, 3477-3492. [CrossRef] 
39. Gutbrod, B.; Haas, D.; Travitzky, N.; Greil, P. Preceramic paper derived alumina/zirconia ceramics. Adv. Eng. Mater. 2011, 13, 494-501. [CrossRef]

40. Junkes, J.A.; Dermeik, B.; Gutbrod, B.; Hotza, D.; Greil, P.; Travitzky, N. Influence of coatings on microstructure and mechanical properties of preceramic paper-derived porous alumina substrates. J. Mater. Process. Technol. 2013, 213, 308-313. [CrossRef]

41. Stares, S.L.; Kirilenko, A.; Fredel, M.C.; Greil, P.; Wondraczek, L.; Travitzky, N. Paper-derived bioactive glass tape. Adv. Eng. Mater. 2013, 15, 230-237. [CrossRef]

42. Stares, S.L.; Fredel, M.C.; Greil, P.; Travitzky, N. Paper-derived hydroxyapatite. Ceram. Int. 2013, 39, 7179-7183. [CrossRef]

43. Stares, S.L.; Fredel, M.C.; Greil, P.; Travitzky, N. Paper-derived $\beta$-TCP. Mater. Lett. 2013, 98, 161-163. [CrossRef]

44. Scheid, D.; Cherkashinin, G.; Ionescu, E.; Gallei, M. Single-source magnetic nanorattles by using convenient emulsion polymerization protocols. Langmuir 2014, 30, 1204-1209. [CrossRef] [PubMed]

45. Rüttiger, C.; Mehlhase, S.; Vowinkel, S.; Cherkashinin, G.; Liu, N.; Dietz, C.; Stark, R.W.; Biesalski, M.; Gallei, M. Redox-mediated flux control in functional paper. Polymer 2016, 98, 429-436. [CrossRef]

46. Vowinkel, S.; Malz, F.; Rode, K.; Gallei, M. Single-source macroporous hybrid materials by melt-shear organization of core-shell particles. J. Mater. Sci. 2017, 52, 11179-11190. [CrossRef]

47. von Irmer, J.; Vowinkel, S.; Scheid, D.; Schöttner, S.; Rüttiger, C.; Appold, M.; Gallei, M. Surface-initiated atom transfer radical polymerization of electrochemically responsive cobalt-methacrylates. Polymer 2017, 122, 303-311. [CrossRef]

48. Vowinkel, S.; Boehm, A.; Schäfer, T.; Gutmann, T.; Ionescu, E.; Gallei, M. Preceramic core-shell particles for the preparation of hybrid colloidal crystal films by melt-shear organization and conversion into porous ceramics. Mater. Des. 2018, 160, 926-935. [CrossRef]

49. Advincula, R.C. Surface initiated polymerization from nanoparticle surfaces. J. Disp. Sci. Technol. 2003, 24, 343-361. [CrossRef]

50. Zoppe, J.O.; Ataman, N.C.; Mocny, P.; Wang, J.; Moraes, J.; Klok, H.A. Surface-initiated controlled radical polymerization: State-of-the-art, opportunities, and challenges in surface and interface engineering with polymer brushes. Chem. Rev. 2017, 117, 1105-1318. [CrossRef] [PubMed]

51. Siegwart, D.J.; Oh, J.K.; Matyjaszewski, K. ATRP in the design of functional materials for biomedical applications. Prog. Polym. Sci. 2012, 37, 18-37. [CrossRef]

52. Mazurowski, M.; Sondergeld, K.; Elbert, J.; Kim, C.J.; Li, J.; Frielinghaus, H.; Gallei, M.; Stühn, B.; Rehahn, M. Polystyrene brushes on fully deuterated organic nanoparticles by surface-initiated nitroxide-mediated radical polymerization. Macromol. Chem. Phys. 2013, 214, 1094-1106. [CrossRef]

53. Braunecker, W.A.; Matyjaszewski, K. Controlled/living radical polymerization: Features, developments, and perspectives. Prog. Polym. Sci. 2007, 32, 93-146. [CrossRef]

54. Zeschky, J.; Höfner, T.; Arnold, C.; Weißmann, R.; Bahloul-Hourlier, D.; Scheffler, M.; Greil, P. Polysilsesquioxane derived ceramic foams with gradient porosity. Acta Mater. 2005, 53, 927-937. [CrossRef]

55. Emmerling, S.G.; Langer, L.B.; Pihan, S.A.; Lellig, P.; Gutmann, J.S. Patterning of a surface immobilized atrp initiator with an inkjet printer. Macromolecules 2010, 43, 5033-5042. [CrossRef]

56. Mazurowski, M.; Gallei, M.; Rehahn, M. Convenient quantification of accessible surface-attached ATRP initiators and RAFT chain transfer agents on cross-linked polystyrene nanoparticles. ACS Macro Lett. 2012, 1, 1362-1366. [CrossRef]

57. Mazurowski, M.; Gallei, M.; Li, J.; Didzoleit, H.; Stühn, B.; Rehahn, M. Redox-responsive polymer brushes grafted from polystyrene nanoparticles by means of surface initiated atom transfer radical polymerization. Macromolecules 2012, 45, 8970-8981. [CrossRef]

58. Drelich, J.; Chibowski, E.; Meng, D.D.; Terpilowski, K. Hydrophilic and superhydrophilic surfaces and materials. Soft Matter 2011, 7, 9804-9828. [CrossRef]

59. Xin, B.; Hao, J. Reversibly switchable wettability. Chem. Soc. Rev. 2010, 39, 769-782. [CrossRef] [PubMed]

60. Gutmann, T.; Kumari, B.; Zhao, L.; Breitzke, H.; Schöttner, S.; Rüttiger, C.; Gallei, M. Dynamic nuclear polarization signal amplification as a sensitive probe for specific functionalization of complex paper substrates. J. Phys. Chem. C 2017, 121, 3896-3903. [CrossRef]

61. Launer, P.J.; Arkles, B. Infrared Analysis of Organosilicon Compounds: Spectra-structure Correlations; Gelest Inc.: Morrisville, PA, USA, 2013. 
62. Yang, H.; Yan, R.; Chen, H.; Lee, D.H.; Zheng, C. Characteristics of hemicellulose, cellulose and lignin pyrolysis. Fuel 2007, 86, 1781-1788. [CrossRef]

63. Zhou, C.; Fasel, C.; Ishikawa, R.; Gallei, M.; Ikuhara, Y.; Lauterbach, S.; Kleebe, H.J.; Riedel, R.; Ionescu, E. One-pot synthesis of a $\mathrm{C} / \mathrm{SiFeN}(\mathrm{O})$-based ceramic paper with in-situ generated hierarchical micro/nano-morphology. J. Eur. Ceram. Soc. 2017, 37, 5193-5203. [CrossRef]

64. Pujar, V.V.; Cawley, J.D. Effect of stacking faults on the X-ray diffraction profiles of $\beta$-SiC powders. J. Am. Ceram. Soc. 1995, 78, 774-782. [CrossRef]

65. Roth, F.; Waleska, P.; Hess, C.; Ionescu, E.; Nicoloso, N. UV Raman spectroscopy of segregated carbon in silicon oxycarbides. J. Ceram. Soc. Jpn. 2016, 124, 1042-1045. [CrossRef]

66. Rosenburg, F.; Ionescu, E.; Nicoloso, N.; Riedel, R. High-temperature Raman spectroscopy of nano-crystalline carbon in silicon oxycarbide. Materials 2018, 11, 93. [CrossRef] [PubMed]

(C) 2018 by the authors. Licensee MDPI, Basel, Switzerland. This article is an open access article distributed under the terms and conditions of the Creative Commons Attribution (CC BY) license (http://creativecommons.org/licenses/by/4.0/). 